(2) Open Access Full Text Article

\title{
Hemorrhagic retinal macrocysts, simulating choroidal melanoma: a case report
}

This article was published in the following Dove Press journal:

Clinical Ophthalmology

27 May 2013

Number of times this article has been viewed

\author{
Ahmad M Mansour' \\ Mahmoud $O$ Jaroudi ${ }^{2}$ \\ 'Department of Ophthalmology, \\ American University of Beirut, \\ Beirut, Lebanon; ${ }^{2}$ Department \\ of Ophthalmology, Rafic Hariri \\ University Hospital, Beirut, Lebanon
}

Introduction: Hemorrhagic retinal macrocysts are extremely rare retinal lesions that can be mistaken for malignancy with subsequent enucleation. Such a case was diagnosed, by a retina specialist based on ultrasonography, as a choroidal melanoma with exudative retinal detachment and the patient was advised to have brachytherapy.

Case presentation: A 15-year-old Caucasian boy suffered sudden visual loss in the left eye and exam revealed vitreous hemorrhage. Magnetic resonance imaging revealed the mass as hyperintense on T1-weighted images and isointense on T2-weighted images with no enhancement after gadolinium dye. Following scleral buckle, the hemorrhagic retinal macrocyst collapsed gradually over a period of 5 weeks. The patient recovered visual acuity of $6 / 7.5$ at the 1 -year follow up.

Conclusion: A hemorrhagic retinal macrocyst can be erroneously diagnosed as choroidal melanoma. Hints for the presence of retinal macrocysts include: egg shape; cyst wall configuration; no attachment to the choroid; and presence of retinal detachment.

Keywords: choroidal melanoma, retinal macrocyst, retinal detachment

\section{Introduction}

Retinal macrocysts are large cysts commonly found after long-standing retinal detachment $^{1-7}$ and are clinically different from cysticercosis, retinal abscess, and medulloepithelioma. An unusual case of hemorrhagic retinal macrocyst, which was initially diagnosed as a malignant melanoma of the choroid, is presented.

\section{Case presentation}

This 15-year-old Caucasian boy suffered sudden visual loss in the left eye and examination revealed vitreous hemorrhage. There was no history of ocular trauma or bleeding disorder. One month later he was referred to a fellowship trained retinal specialist for evaluation. Choroidal melanoma of the left eye was diagnosed based on ultrasound findings (Figure 1). Brachytherapy was advised. Examination revealed best corrected visual acuity of 20/30, dark round well-delineated inferotemporal retinal mass (Figure 2), inferotemporal dialysis, and shallow inferior retinal detachment. The clinical diagnosis was hemorrhagic retinal macrocyst. Repeat ultrasonography confirmed the smooth cystic contour to the mass. The macrocyst wall was continuous with the retina. The mass had low reflective internal contents without choroidal excavation (Figures 1 and 3). Intravenous fluorescein angiography revealed blockage of fluorescence by the mass (Figure 4). There was autofluorescence of the center and edges of the retinal mass (Figure 5). On magnetic resonance (MR) imaging, the 


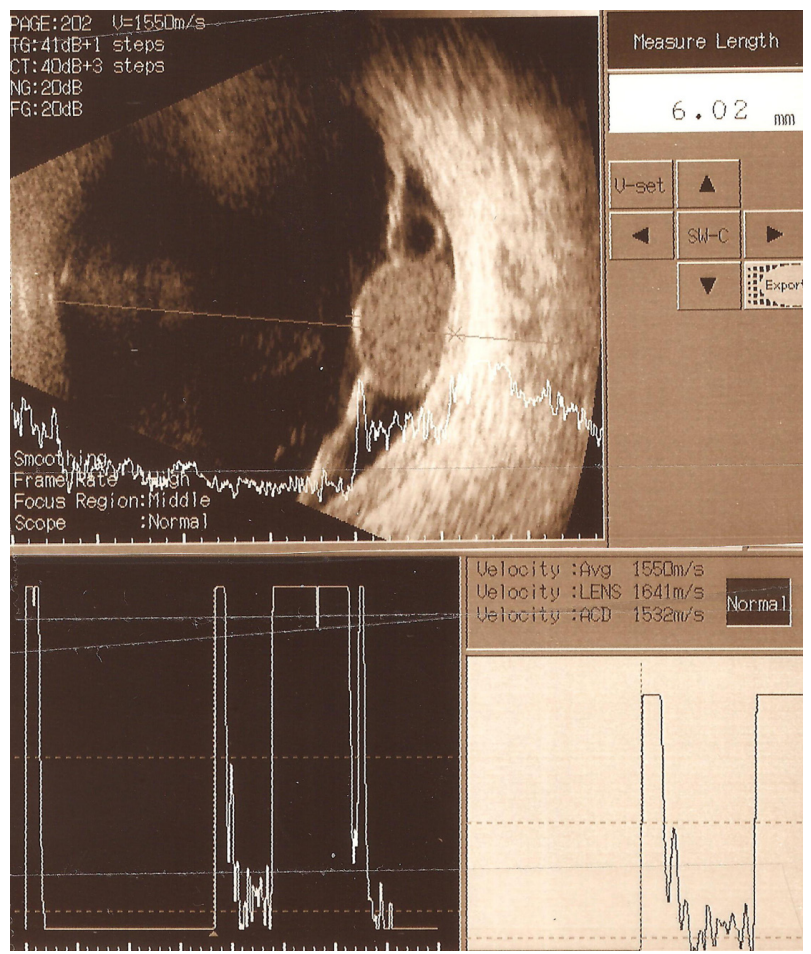

Figure I Ultrasound scan of the left eye.

Notes: Ultrasound scan of the left eye performed at the original clinic (that of the retina specialist who diagnosed melanoma) was interpreted as suggestive of melanoma. A well-delineated cystic mass lesion measuring $8 \mathrm{~mm} \times 6 \mathrm{~mm}$ was noted. It had a high surface reflectivity and low-internal reflectivity with a homogenous echotexture. Another adjacent retinal macrocyst was noted.

mass appeared hyperintense on T1-weighted images and isointense on T2-weighted images. The mass disappeared gradually 5 weeks after scleral buckle with drainage of subretinal fluid (Figure 6). Best corrected vision acuity improved to $6 / 7.5$ at the 1-year follow up.

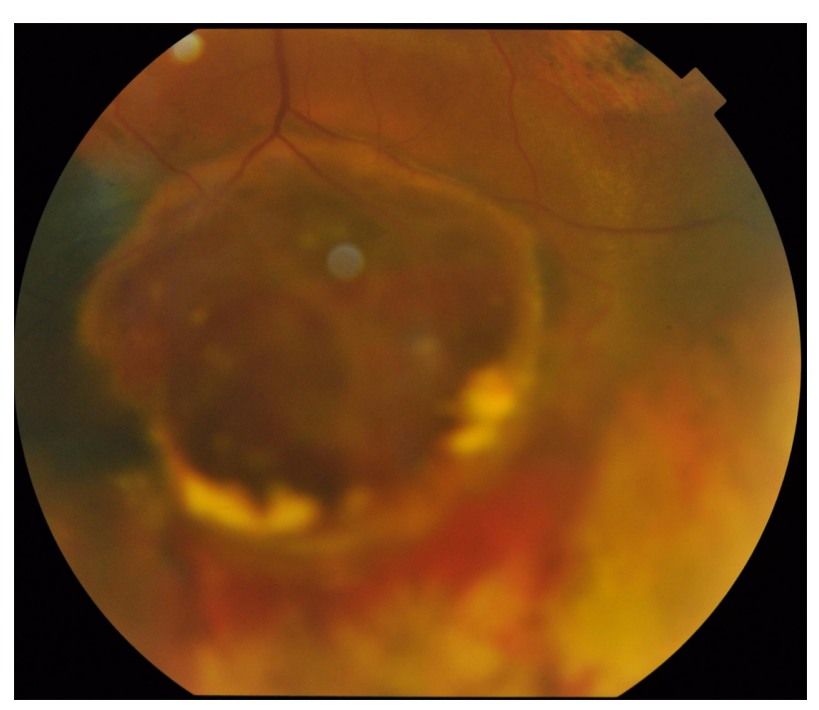

Figure 2 Fundus photograph of the left eye.

Notes: Fundus photograph of the left eye revealed an inferotemporal mass lesion. This well-demarcated dark retinal mass had a smooth cystic contour on presentation.

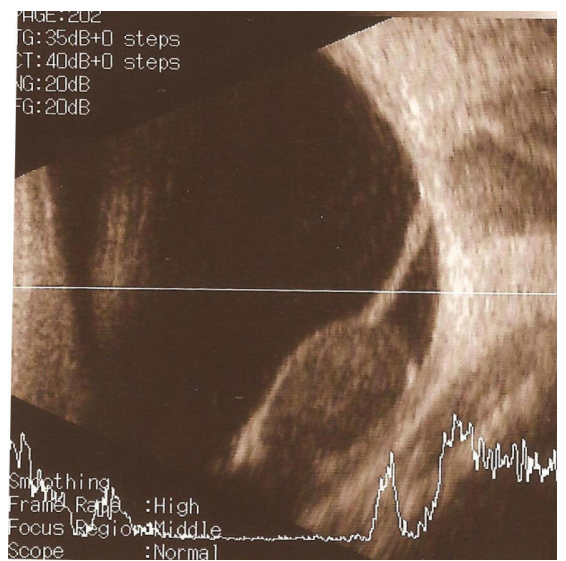

Figure 3 Repeat ultrasound scan of left eye (I week later).

Notes: Repeat ultrasound scan at our clinic. The mass appeared to be encapsulated suggesting a retinal macrocyst. There was an absence of choroidal excavation.

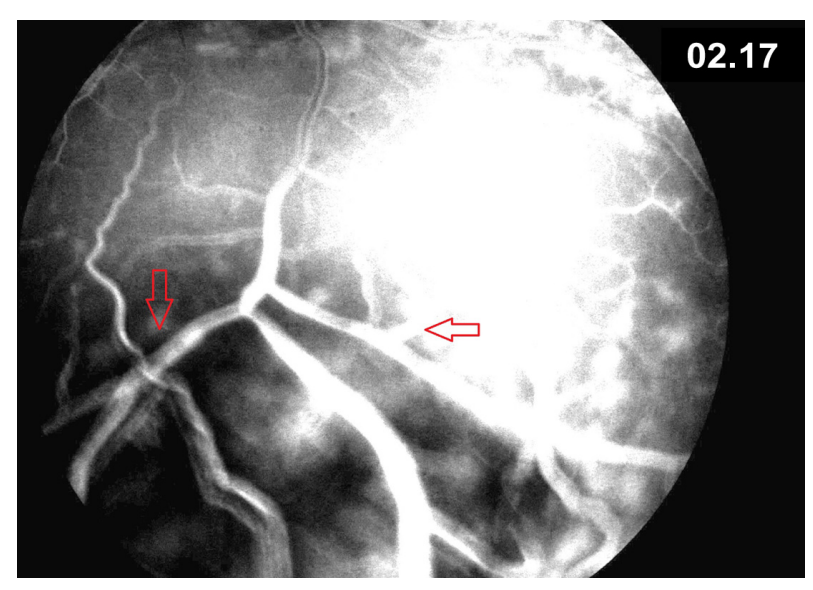

Figure 4 Late frame of fluorescein angiography.

Notes: Late frame of fluorescein angiography: there was blockage of fluorescence by the macrocyst (arrows) with few foci of leakage (retinal mass was mostly hypofluorescent during early, middle and late fluorescein transits with few leakage spots in middle and late phases).

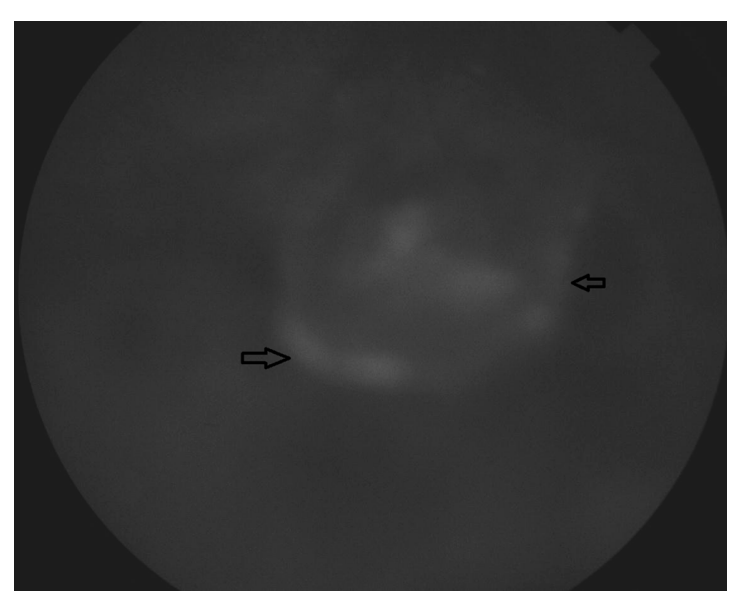

Figure $\mathbf{5}$ Late fluorescein transit of the left eye at presentation.

Notes: There was patchy hyper-autofluorescence of the center and edges of the retinal mass (arrows). 


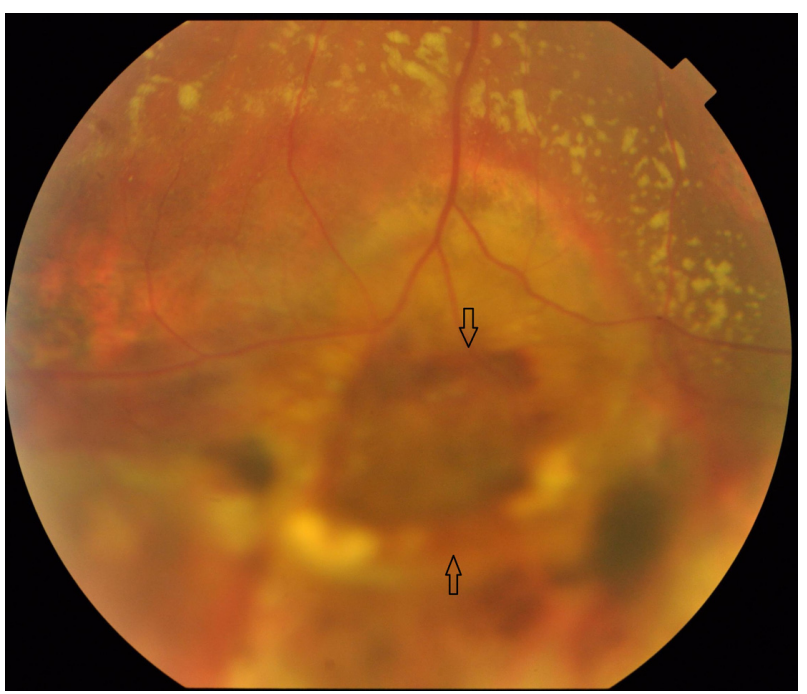

Figure 6 Fundus photograph of the left eye 5 weeks after presentation.

Notes: Fundus photograph of the left eye 5 weeks after presentation. The lesion (arrows) resolved after circumferential scleral buckle and cryopexy to the area of inferotemporal dialysis.

\section{Discussion}

The differential of a peripheral retinal cystic lesion includes retinoschisis, cysticercosis, medulloepithelioma, toxocariasis, localized Coats disease, peripheral choroidal neovascularization, and intraocular choristoma. Retinal macrocysts are usually asymptomatic, single or multiple fluid-filled cavities that are associated with long-standing retinal detachment, particularly of the traumatic type with retinal dialysis. ${ }^{7}$ They arise often from the outer plexiform layer of the retina and require no specific attention during retinal detachment repair. ${ }^{4}$ Surgical collapse of the macrocyst is required only when the macrocyst prevents closure of the primary retinal break. Hemorrhagic macrocysts are rare. The presence of blood in the macrocyst cavity could stem from rupture of the retinal blood vessels lining the macrocyst, ${ }^{4-6}$ bridging retinal vessels over a retinal tear, or peripheral neovascularization. ${ }^{8,9}$
Ruiz $^{1}$ described the enucleation of a blind eye with a long history of retinal detachment. A choroidal melanoma was suspected by funduscopy. However by histopathology this eye contained a retinal macrocyst with organized blood. Vogel $^{2}$ reported two cases also initially diagnosed as choroidal melanoma that were histologically hemorrhagic retinal cysts. Wolter ${ }^{3}$ found a blackish retinal mass during dissection of a blind eye that turned out also to be a blood-filled retinal macrocyst. Rishi et $\mathrm{al}^{4}$ documented the collapse of a large hemorrhagic retinal macrocyst 3 years after a scleral buckle. The current case was a seeing eye, initially diagnosed as choroidal melanoma. Retinal macrocysts usually collapse spontaneously within weeks after successful retinal reattachment. ${ }^{5,6}$

Melanoma of the choroid appears hyperintense on T1-weighted image and hypointense on T2-weighted image. ${ }^{10}$ Acute hemorrhagic macrocyst appears hypointense on T2 images. Subacute hemorrhagic macrocyst has heterogeneous signals on T1 and T2 images. Chronic hemorrhagic macrocyst appears hyperintense on both $\mathrm{T} 1$ and $\mathrm{T} 2$ images. ${ }^{10}$ Hence MR signals are generally of little help to differentiate between melanoma and hemorrhagic retinal cyst except in chronic hemorrhagic cysts (Table 1). In the current case the cyst has similar MR features to that of a melanoma.

There is usually blockage of autofluorescent light by intraretinal blood in hemorrhagic retinal macrocyst. Choroidal melanoma displays variable degrees of autofluorescence depending on the state of the overlying retinal pigment epithelium, the presence of orange pigment, the size and the pigmentation of the tumor. ${ }^{11}$ Shields et al ${ }^{11}$ detected the following percentages in 51 consecutive patients with choroidal melanoma: hypo-autofluorescence (39\%), isoautofluorescence (6\%) and hyper-autofluorescence (55\%) (Table 1). In the current case, there was autofluorescence of the center and edges of the macrocyst, a feature that cannot be used to differentiate it from a melanoma.

Table I Differentiating signs between choroidal melanoma and hemorrhagic retinal macrocyst

\begin{tabular}{lll}
\hline & Choroidal melanoma & Hemorrhagic retinal macrocyst \\
\hline Shape & Dome or mushroom & Egg \\
Configuration & Irregular or oblong & Cyst wall \\
Magnetic resonance imaging & Hyperintense on TI & Acute hemorrhagic macrocyst: hypointense on T2; chronic \\
& Hypointense on T2 & hemorrhagic macrocyst: hyperintense on TI and T2 \\
Ultrasound & Low or moderate internal reflectivity & Low or moderate internal reflectivity \\
Autofluorescence & Hypo-autofluorescence (39\%); isoautofluorescence (6\%); & Blockage in most cases \\
& hyper-autofluorescence (55\%) & Intense hypo-fluorescence \\
Fluorescein angiography & Hypo-fluorescence in small tumors; patchy pattern & \\
& of early hypo-fluorescence and hyper-fluorescence & \\
& followed by late intense staining in large tumors &
\end{tabular}


In conclusion a macrocyst of the retina filled with organized hemorrhage is one more example of a condition which can be erroneously diagnosed as choroidal melanoma even with current technological advances. Egg shape, cyst wall configuration, and associated rhegmatogenous retinal detachment are some hints for the correct diagnosis of hemorrhagic retinal macrocysts.

\section{Acknowledgment}

The authors have obtained written, informed consent from the patient for publication of this case report.

\section{Disclosure}

The authors declare no conflicts of interest.

\section{References}

1. Ruiz RS. Hemorrhagic macrocyst of the retina. mistaken for malignant melanoma of the choroid. Arch Ophthalmol. 1970;83:588-590.

2. Vogel MH. Makrozysten der netzhaut blut gefüllt. Ein beitrag zur differentialdiagnose des malignen melanoms der aderhaut. [Blood-filled macrocysts of the retina. A contribution to the differential diagnosis of malignant melanoma of the choroid]. Klin Monbl Augenheilkd. 1975;167:855-864. German.
3. Wolter JR. Blood-filled macrocyst of the peripheral retina. Surv Ophthalmol. 1964;118:135-138.

4. Rishi P, Rishi E, Sen PR, Sharma T. Hemorrhagic intraretinal macrocyst: Differential diagnoses and report of an unusual case. Oman J Ophthalmol. 2011;4:28-31.

5. Goel SD, Augsburger JJ. Hemorrhagic retinal macrocysts in advanced Coats disease. Retina. 1991;11:437-440.

6. Conway BP, Welch RB. X-chromosone-linked juvenile retinoschisis with hemorrhagic retinal cyst. Am J Ophthalmol. 1977;83:853-855.

7. Marcus DF, Aaberg TM. Intraretinal macrocysts in retinal detachment. Arch Ophthalmol. 1979;97:1273-1275.

8. Verdaguer P, Nadal J. Intraretinal cyst secondary to longstanding retinal detachment. Eur J Ophthalmol. 2012;22:506-508.

9. Labriola LT, Brant AM, Eller AW. Chronic retinal detachment with secondary retinal macrocyst and peripheral neovascularization. Semin Ophthalmol. 2009;24:2-4.

10. Stroszczynski C, Hosten N, Bornfeld N, et al. Choroidal hemangioma: MR findings and differentiation from uveal melanoma. Am J Neuroradiol. 1998;19:1441-1447.

11. Shields CL, Bianciotto C, Pirondini C, Materin MA, Harmon SA, Shields JA. Autofluorescence of choroidal melanoma in 51 cases. $\mathrm{Br} J$ Ophthalmol. 2008;92:617-622.
Clinical Ophthalmology

\section{Publish your work in this journal}

Clinical Ophthalmology is an international, peer-reviewed journal covering all subspecialties within ophthalmology. Key topics include: Optometry; Visual science; Pharmacology and drug therapy in eye diseases; Basic Sciences; Primary and Secondary eye care; Patient Safety and Quality of Care Improvements. This journal is indexed on

Submit your manuscript here: http://www.dovepress.com/clinical-ophthalmology-journal

\section{Dovepress}

PubMed Central and CAS, and is the official journal of The Society of Clinical Ophthalmology (SCO). The manuscript management system is completely online and includes a very quick and fair peer-review system, which is all easy to use. Visit http://www.dovepress.com/ testimonials.php to read real quotes from published authors. 